\title{
Passive Power Decoupling Approach for Three-Level Single-Phase Impedance Source Inverter Based on Resonant and PID Controllers
}

\author{
Elena Makovenko ${ }^{1,2}$, Oleksandr Husev ${ }^{1,4}$, Janis Zakis ${ }^{3}$, Carlos Roncero-Clemente ${ }^{2}$, Enrique Romero-Cadaval ${ }^{2}$, Dmitri Vinnikov ${ }^{1}$ \\ ${ }^{1}$ Tallinn University of Technology (Estonia) \\ ${ }^{2}$ Power Electrical and Electronic Systems (PE\&ES), University of Extremadura, Badajoz (Spain) \\ ${ }^{3}$ Institute of Industrial Electronics and Electrical Engineering, Riga Technical University, Riga (Latvia) \\ ${ }^{4}$ Chernihiv National University of Technology (Ukraine) \\ elmako@ttu.ee, oleksandr.husev@ieee.org
}

\begin{abstract}
Single-phase inverter suffers from doublefrequency power ripples in the input side transferred there from the ac-side. To mitigate this ripple, two types of power decoupling approaches can be applied: passive power decoupling and active power decoupling. We present a technique of passive power decoupling realized by modifying the control strategy. The main idea is to produce the timevarying shoot-through duty cycle to charge and discharge impedance capacitors when needed in the desired sequence for mitigating input power ripple without deteriorating the output power quality. The main contribution of the paper is in the determination of the parameters of a regulator taking into account the dynamic feature of the quasi-Z-source network. The validity of the proposed control strategy was confirmed by simulation results in PSCAD. The results show that this strategy can be applied for practical applications.
\end{abstract}

Keywords - passive decoupling; single-phase inverter; PR controller; double-frequency ripple; distorted grid; quasi-Z source.

\section{INTRODUCTION}

During the two last decades, the integration of impedance networks in different fields of application, in particular in Photovoltaic (PV) systems, has been under wide discussion. Different configurations of impedance networks proposed in [1]-[8] allow preventing limitations of the Voltage Source Inverters (VSIs). The Shoot-Through (ST) state is introduced in the system in order to provide boost function without an additional conversion stage. The ST improves the reliability of the system because of absence of any forbidden states.

The qZ-source Neutral-Point-Clamped (NPC) inverter presented in [9] allows use of the single or separated input source(s) to reduce the voltage stress across the switching devices, thus increasing the switching frequency.

Another important feature of the inverter is the capability of injecting current into the distorted LV grid with the required quality set by international standards such as IEEE519 [10]. Different types of controllers are used to control the quality of the output current injected [11], [12]-[14].
The PR controller looks most promising since it can provide stable fundamental current injection along with Harmonic Compensation (HC) [15].

At the same time, the single-phase system suffers from such drawback as Double-Frequency Ripple (DFR) of input power. Several strategies are reported in the literature to reduce the DFR [16], [17]. These strategies are divided into two types: passive decoupling [18] that means the system has no additional switching devices and active decoupling [19], [20] containing additional switching devices. This paper focuses on passive power decoupling. The purpose of passive power decoupling is to maintain the average voltage of the dc-link with limited second-order fluctuations across it to reduce the same in the input power. Most of the approaches are based on a modified control strategy without configuration changes[18].

Also, the mitigation of input power pulsation can be achieved by means of increasing the values of the passive components [21], [22]. At the same time, it is evident that the size of these components will be larger.

The main problem here is in the oversized passive components used for simulation and experimental verification of the proposed algorithms [16], [18], [21].

The aim is to develop a novel approach based on resonant and PID controllers for passive decoupling. It is clearly demonstrated that such approach is capable of mitigating DFR in the case of optimized passive elements.

\section{CASE STUDY SYSTEM DESCRIPTION}

The case study system is depicted in Fig. $1 a$. It consists of the Three-Level (3L) single-phase Neutral-Point-Clamped (NPC) quasi-Z-Source Inverter (qZSI) connected to the distorted grid through an LCL-filter. This topology is described in [23]. Grid voltage contains $5^{\text {th }}$ harmonic that is about $3 \%$ from the fundamental one. A PV installation of 10 serial modules is a voltage source for the selected topology. The calculation of passive components is presented below, with summarized values given in Table I. 


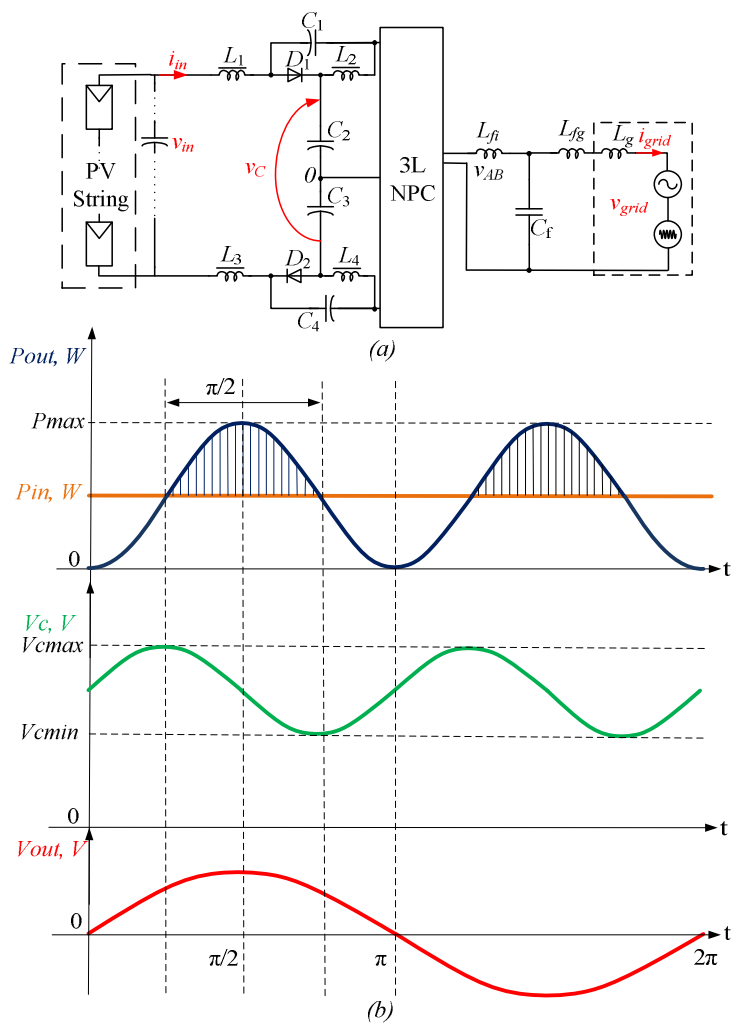

Fig. 1. Single-phase PV system using $3 \mathrm{~L}$ NPC qZSI $(a)$; idealized waveforms of the output power along with desirable input power, voltage across impedance source capacitors and grid voltage over one line cycle $(b)$.

\section{A. Passive elements estimation}

The following assumptions were accepted for the topology studied: $C_{1}=C_{2}=C_{3}=C_{4}=C ; L_{1}=L_{2}=L_{3}=L_{4}$; in the steady state mode, the inductors current is equal; therefore, the capacitors current is equal as well. It will be valid under proper control strategy discussed in the next section. The minimum value of the ST duty cycle $\left(D_{\min }\right)$ depends on the value of the input voltage $\left(V_{i n}\right)$ and the desired minimum value of the output voltage $\left(V_{d c_{-} \min }\right)$ :

$$
D_{\text {min }}=0.5 \cdot\left(1-\frac{V_{\text {in }}}{V_{d c_{-} \min }}\right) \text {. }
$$

This value should exceed zero to ensure that PR controller operates in linear range.

The average voltage across the capacitors of the qZS network depends on the average value of ST duty cycle $(D)$. The average voltage across the capacitors $C_{1}, C_{2}, C_{3}, C_{4}$ is expressed as [23]:

$$
\begin{gathered}
V_{C 2}=V_{C 3}=\frac{1-D}{1-2 D} \cdot \frac{V_{\text {in }}}{2}, \\
V_{C 1}=V_{C 4}=\frac{D}{1-2 D} \cdot \frac{V_{\text {in }}}{2} .
\end{gathered}
$$

Fig. $1 b$ shows the idealized waveforms of the output power along with desirable input power, voltage across impedance capacitors and grid voltage over one line cycle $\left(f_{\text {line }}=50 \mathrm{~Hz}\right)$.

The time $\pi / 4<t<3 \pi / 2$ corresponds to the realizing energy mode. During that time, capacitors are discharging to maintain the input power at the average value. The time $3 \pi / 2<t<5 \pi / 4$ corresponds to the storage energy mode. During that time, capacitors are charging for the same reason.

According to Fig. $1 b$, the frequency is fixed at the double line frequency and the amplitude is $\pm 100 \%$ of the output average power (neglecting losses). It is assumed that the voltage ripple across the capacitors will be distributed evenly.

$$
\Delta V_{C 1}=\Delta V_{C 2}=\Delta V_{C 3}=\Delta V_{C 4}=\frac{\Delta V_{d c}}{4},
$$

where $\Delta V_{d c}$ is available pulsation in the dc-link.

The maximum and minimum voltages across the capacitors are:

$$
\begin{aligned}
& V_{C 1_{-} \text {max }}=V_{C 1}+\frac{\Delta V_{C 1}}{2} ; V_{C 2_{-} \max }=V_{C 2}+\frac{\Delta V_{C 2}}{2}, \\
& V_{C 1_{-} \text {min }}=V_{C 1}-\frac{\Delta V_{C 1}}{2} ; V_{C 2_{-} \text {min }}=V_{C 2}-\frac{\Delta V_{C 2}}{2} .
\end{aligned}
$$

The input power ripple is calculated according to the following equation:

$$
\Delta P=\frac{2}{\pi} \int_{0}^{\pi / 2}\left(P_{\max }-P_{i n}\right) \sin (2 \omega t) d \omega t .
$$

The energy that must be stored in the impedance capacitors in order to mitigate the ripple is defined as:

$$
\Delta E=\Delta P \cdot \frac{T}{4}=\frac{P_{i n} T}{2 \pi},
$$

where $T$ is the fundamental period.

This energy is distributed between capacitors $C_{1}$ and $C_{2}$ according to the voltage variation:

$$
\begin{aligned}
& \Delta E_{1}=\frac{C\left(V_{C 1 \_ \text {max }}^{2}-V_{C 1 \_ \text {min }}^{2}\right)}{2}=C \cdot V_{C 1} \cdot \Delta V_{C}, \\
& \Delta E_{2}=\frac{C\left(V_{C 2 \_ \text {max }}^{2}-V_{C 2 \_ \text {min }}^{2}\right)}{2}=C \cdot V_{C 2} \cdot \Delta V_{C} .
\end{aligned}
$$

Finally, the total energy can be expressed as:

$\Delta E=2 \Delta E_{1}+2 \Delta E_{2}=2 C \cdot V_{C 1} \cdot \Delta V_{C}+2 C \cdot V_{C 2} \cdot \Delta V_{C}$.

From (11), the value of the capacitor can be calculated:

$$
C=\frac{P_{i n} \cdot T}{4 \pi \cdot \Delta V_{d c}\left(V_{C 1}+V_{C 2}\right)} .
$$

Considering that DFR is compensated by the control system and capacitors, the inductor of the impedance network can be selected taking into account high frequency current ripple only. The following expression is presented in many papers:

$$
L_{1}=L_{2}=L_{3}=L_{4} \geq \frac{V_{\text {in }}{ }^{2} \cdot(1-D) \cdot D}{2 \cdot P_{\text {in }} \cdot f_{S} \cdot K_{I} \cdot(1-2 \cdot D)},
$$

where $K_{I}$ is a current ripple factor and $f_{S}$ is switching frequency. 


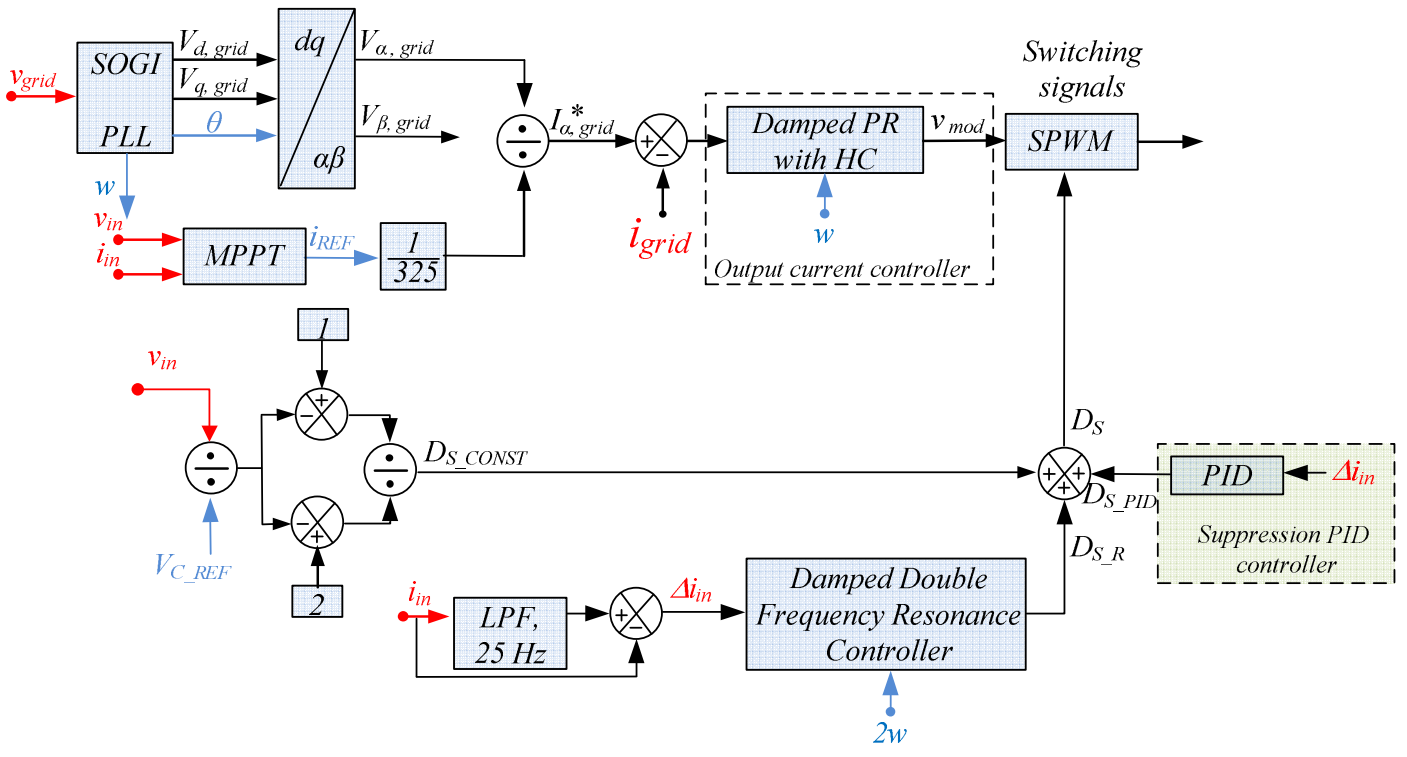

Fig. 2. Block diagram of the proposed control strategy.

\section{CONTROL SYSTEM DESCRIPTION}

The proposed control strategy is presented in Fig. 2. The control system can be divided into two parts. The first part provides the desirable value of the dc-link voltage, the other one controls the quality of the output current, which will be injected into the distorted grid.

\section{A. Output current controller}

In order to produce the output current that will be injected into the distorted grid with THD that satisfies the international standards (it should be less than 5\%), the LCL output filter and damped PR controller with the Harmonic Compensation (HC) approach were applied. HC was applied to attenuate the value of the $3^{\text {rd }}, 5^{\text {th }}, 7^{\text {th }}, 9^{\text {th }}$ order harmonics. Detailed tuning of the PR controller for $3 \mathrm{~L}$ NPC qZSI is discussed in [12]. The damped PR controller was selected because it provides high gain at the tuning frequency over a wider band in comparison with the conventional PR controller. Comparison of a conventional PR controller and a damped PR controller is presented in [15]. The damped PR controller with the HC transfer function is:

$$
G_{d P R_{-} H C}=K_{p}+\Sigma \frac{K_{H} s}{s^{2}+2 \omega_{C H} s+\omega_{H}^{2}},
$$

where $H$ is the harmonic order, $w_{C H}$ is cut-off frequency that is defined for each harmonic separately.

The applied control strategy of the SPWM is described in [24]. It is reported that the carrier signal of the ST state has double frequency that relates to the carrier signals of the active state. Thus, in the proposed case, we obtain: $f_{s w}=50 \mathrm{kHz}$ when $D s=0$, and $f_{s w}=100 \mathrm{kHz}$ when $D s>0$.

The value of the $D_{S_{-} \text {CONST }}$ provides an average value of the $\mathrm{ST}$ required to maintain the average voltage in the inner capacitors $V_{C}$.

\section{B. Resonant suppression controller}

The function of the suppression controller is to acquire the desirable voltage fluctuation in the dc-link that should provide the corresponding voltage fluctuation across impedance capacitors, which allows reducing the power fluctuation in the input side by means of the time-varying of the ST duty cycle. Detailed description is provided in [18] and a resonant controller is proposed in order to suppress the DFR.

The same structure is used in this paper. It has been shown that qZSI may have right half-hand plane zero that limits the system dynamic response. It is a typical nonminimum system. At the same time, the study above has overlooked the possible problems with fluctuations of the input current due to the resonance in the qZS network.

Fig. 3 shows a dynamic model of the input current control loop. It is based on the qZSI small signal model presented in several papers [25]-[27]. It has been shown before that the dynamic behavior of the qZS network strictly depends on the value of the passive components. In the studied case, the value of passive components was selected in order to provide the demanded input and output current quality. At the same time, it cannot be oversized because of practical reasons. As a result, the control system should be tuned for optimal passive component values.

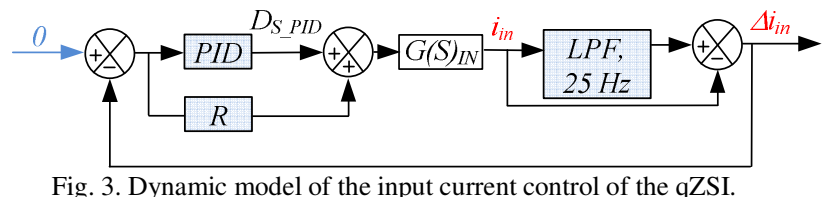

The $G(S)_{I N}$ transfer function is derived from the small signal model of qZSI and defines the link between the ST duty cycle and the input current variation. The main purpose of this loop is to suppress possible input current fluctuations connected with the resonance feature of the qZS network. 


\section{COMPARATIVE ANALYSIS OF THE PROPOSED CONTROL SYSTEM}

This section describes the proposed modification of the control strategy in detail and presents a comparative analysis of our approach and other approaches proposed before.

Fig. 4 shows the root locus diagrams of the dynamic model depicted in Fig. 3. Fig. $4 a$ shows the diagram of the system without a PID controller; Fig. $4 b$ shows the diagram of the system with a PID controller. As can be seen, the qZsource inverter with a resonant controller and without a PID controller has roots and zeros that are very close to the axes center. As a result, the system is very sensitive and has complex dynamic behavior.

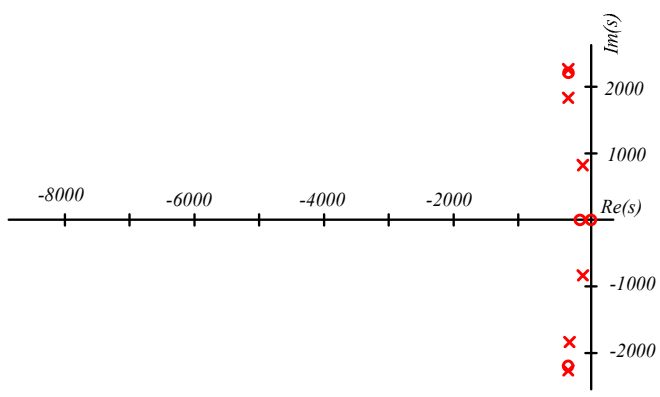

(a)

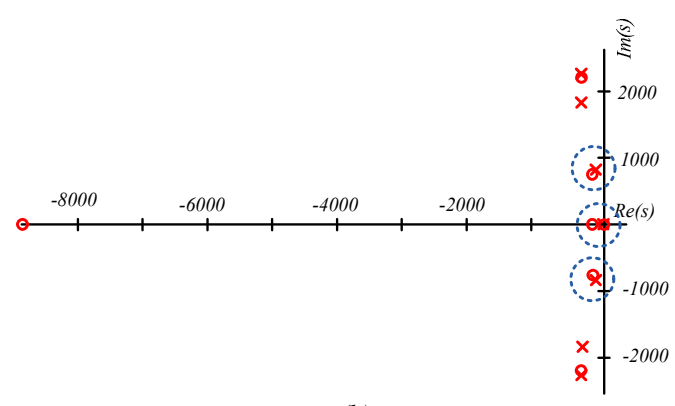

(b)

Fig. 4. Root locus diagram of the input current control transfer function without (a) and with (b) PID controller.

Fig. $4 b$ shows that adding of a PID controller leads to additional poles and zeros that compensate already existing roots and zeros. As a result, better dynamic performance is expected.

Theoretically, it is possible to tune a PID controller in order to completely eliminate some poles and zeros. But in practical applications it is not possible because of limited passive elements tolerance.

Fig. 5 shows the Bode diagram of the input current control transfer function with a resonant controller but without a PID controller. The system has several resonance peaks, the left one corresponds to the resonant controller, while the right one corresponds to the qZS network resonance frequency.

The main point is that phase shift approaches 180 degrees in the high frequency domain. To shift zeros and poles deeper in the left half-plane, an additional PID controller was applied. The Bode diagram of PID controllers is shown in Fig. 6 and the body diagram of the open loop full transfer function is shown in Fig. 7.
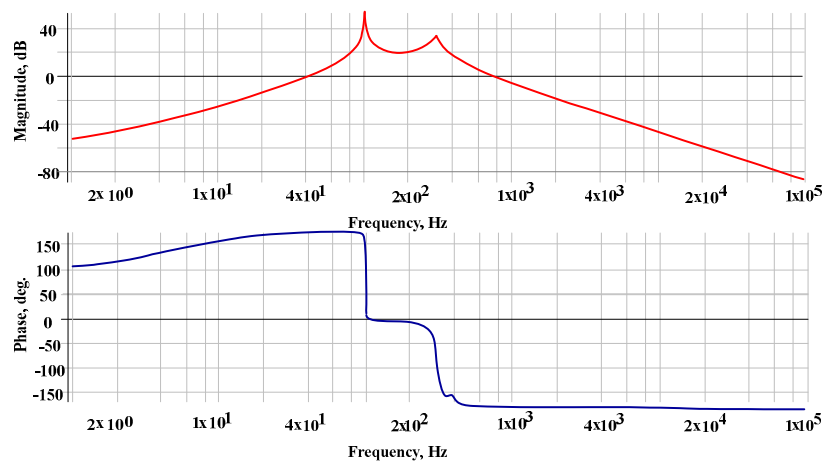

Fig. 5. Bode diagram of the open loop input current control transfer function with a resonant controller.

It can be seen that the PID controller introduces an additional phase lead and the summarized phase shift is closer to 0 degrees, as depicted in Fig. 7. The PID controller corrects phase shifting along with the smoothest gain in the whole range of the frequency domain. As a result, the system is more stable and predicted.
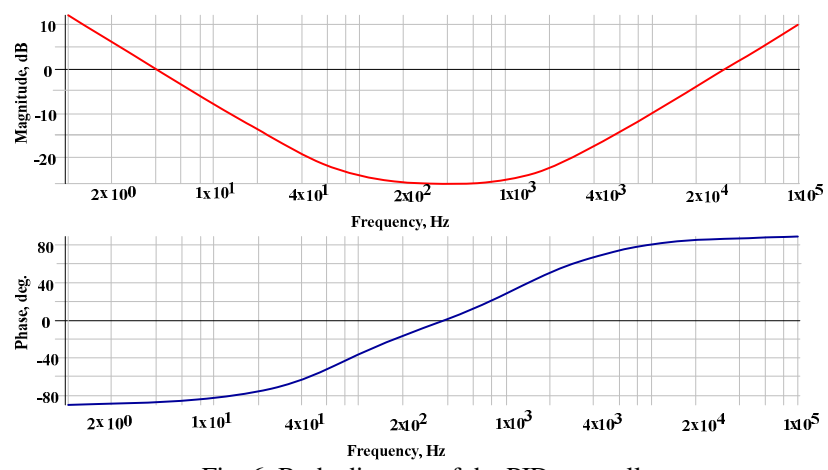

Fig. 6. Bode diagram of the PID controller.
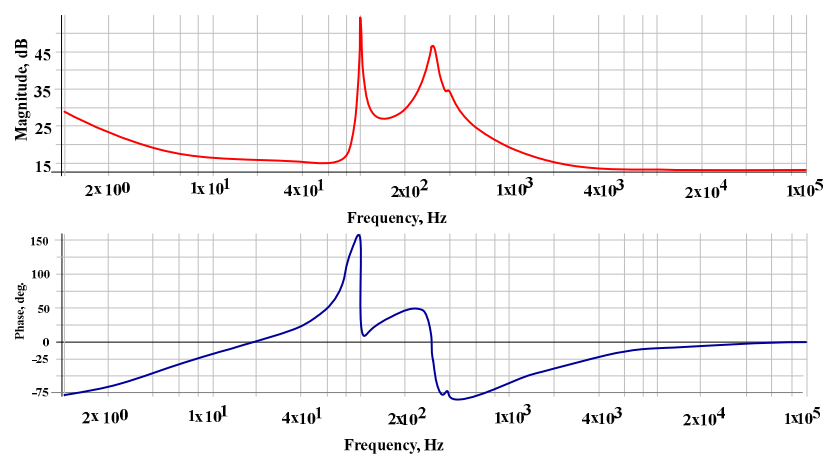

Fig. 7. Bode diagram of the open loop input current control transfer function with resonant and PID controllers.

\section{SIMULATION RESUlts}

Table 1 presents the parameters of the study system that was used in the simulation. Fig. 8 shows the simulation results by using the $\mathrm{R}$ term $(a)$; by using the $\mathrm{R}$ term with the PID controller $(b)$; transient time by using the $\mathrm{R}$ term with the PID controller $(c)$. From top to bottom: input power; summarized voltage across the impedance capacitors and voltage across impedance capacitors separately; ST dutycycle; grid voltage and current. 
TABLE 1. PARAMETERS OF THE 3L SINGLE PHASE QZSI UNDER STUDY

\begin{tabular}{|c|c|}
\hline Parameters & Value \\
\hline \multicolumn{2}{|c|}{ General parameters } \\
\hline$V_{\text {in }}$ & $360 \mathrm{~V}$ \\
\hline$V_{\text {Grid }}$ & $230 \mathrm{~V} \mathrm{ac}$ \\
\hline$V_{d c \_a v e}$ & $474 \mathrm{~V}$ \\
\hline$V_{d c \text { peak to peak }}$ & $68 \mathrm{~V}$ \\
\hline$f_{\text {switching }}$ & $50 \mathrm{kHz}(100 \mathrm{kHz})$ \\
\hline$f_{\text {line }}$ & $50 \mathrm{~Hz}$ \\
\hline \multicolumn{2}{|c|}{ Passive components } \\
\hline$C_{1}, C_{2}, C_{3}, C_{4}$ & $0.7 \mathrm{mF}$ \\
\hline$L_{1}, L_{2}, L_{3}, L_{4}$ & $0.240 \mathrm{mH}$ \\
\hline$R_{q Z S}$ & $0.1 \mathrm{Ohm}$ \\
\hline$L_{f i}$ & $0.44 \mathrm{mH}$ \\
\hline$L_{f g}$ & $0.22 \mathrm{mH}$ \\
\hline$C_{f}$ & $15,47 \mathrm{uF}$ \\
\hline$R_{f}$ & $0.1 \mathrm{Ohm}$ \\
\hline \multicolumn{2}{|c|}{ Input current controller: PID with Resonant controller } \\
\hline$P I D(P)$ & 0.05 \\
\hline$P I D(I)$ & 0.04 \\
\hline$P I D(D)$ & 5 us \\
\hline$R$ & 10 \\
\hline \multicolumn{2}{|c|}{ Output current Proportional-Resonant controller } \\
\hline$K_{P}$ & 0.5 \\
\hline$K_{1}, K_{3}, K_{5}, K_{7}, K_{9}$ & $100 ; 100,150,10,20$ \\
\hline$v_{C l}, w_{C 3}, w_{C 5}, w_{C 7}, w_{C 9}$ & $0.314,3.14,3.14,3.14,3.14$ \\
\hline
\end{tabular}

In Fig. $8 b$, the ripple of the input power is $533 \mathrm{~W}$ while the average input power is $1800 \mathrm{~W}$, the ripple across impedance capacitors is $68 \mathrm{~V}$ and $17 \mathrm{~V}$ across each capacitor separately, which corresponds to the calculation results; the ST duty cycle has high frequency ripple to mitigate fast dynamic pulsation in the input power, the THD of the grid current is about $5 \%$. Fig. $8 a$ shows that obviously the $\mathrm{R}$ term is not enough to achieve the desired purpose. The ripple of the input power is significant. The quality of the output power was deteriorated. Fig. $8 c$ presents the transient time from zero to $0.8 \mathrm{sec}$. at the moment of time the relay connects the inverter to the grid. At the moment of time $0.2 \mathrm{sec}$, the inverter starts to operate without the input current mitigation algorithm. Finally, at the moment of time $0.5 \mathrm{sec}$, the proposed control strategy starts to work.

\section{CONCLUSIONS}

This paper presents the technique of passive power decoupling realized by the modified control strategy based on the resonant with PID controllers. It was shown that the resonant controller cannot provide the satisfied operation mode of the passive decoupling approach due to the possible resonance in the qZS network while the application of the PID controller allows elimination of some zeros and poles, resulting in the stable system.
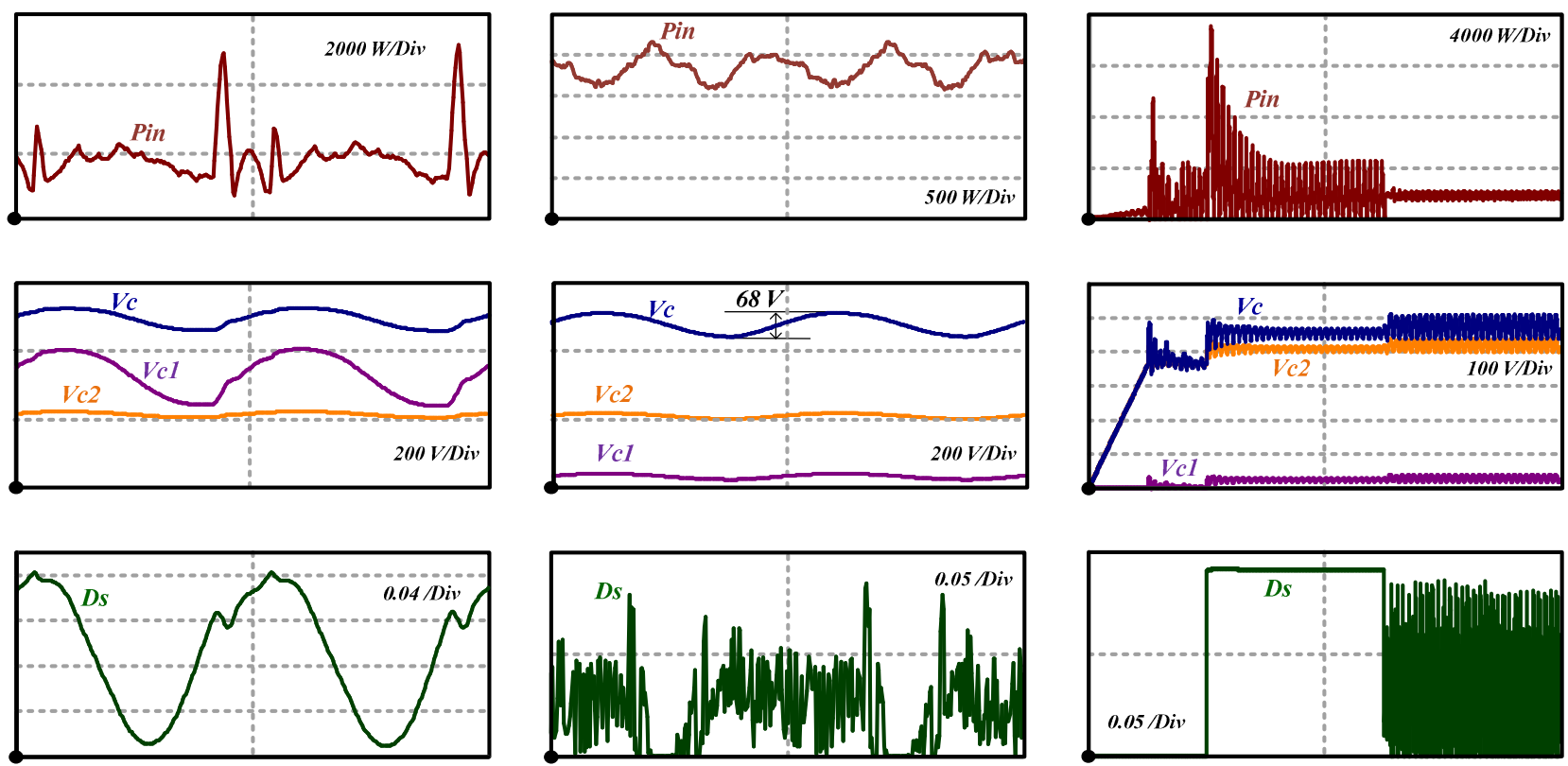

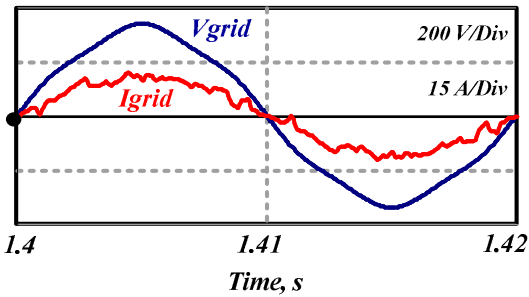

(a)

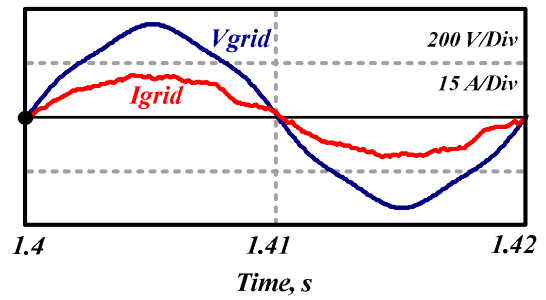

(b)

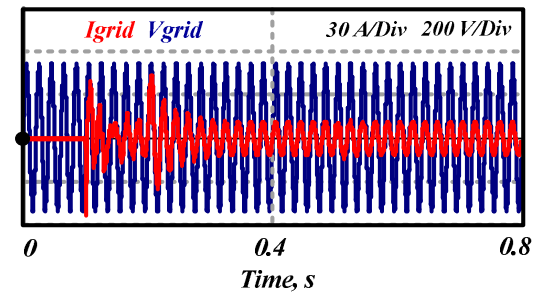

(c)

Fig. 8. Simulation results with a resonant controller (a); simulation results with a resonant and a PID controller (b); simulation results of transient time with a resonant and a PID controller (c). 
The main idea of passive decoupling is to charge and discharge the impedance capacitors when it is needed. The capacitors of the impedance network should be able to absorb the required ripple energy. Based on this statement, the passive components of the impedance network were calculated. When the grid reduces the consumption of power, the capacitors are discharging and return that energy when the demand of power by the grid is increasing; as a result, the fluctuation of the input power is minimized. For proper work of the resonant term, the ST should exceed zero in all operation modes. Thus, the dc-link voltage is nonfixed, the voltage stress of the switching devices is increasing as compared to the control strategy without the decoupling approach but for low voltage applications and for the $3 \mathrm{~L}$ converter, this value is not critical. The simulation results confirm the validity of the studied work. The ripple of the input power is $30 \%$ at nominal power while the fluctuation confirmed theoretical predictions.

\section{ACKNOWLEDGMENT}

This research was supported by Latvian Council of Science (Grant 673/2014) and the Estonian Centre of Excellence in Zero Energy and Resource Efficient Smart Buildings and Districts, ZEBE, grant 2014-2020.4.01.150016 funded by the European Regional Development Fund and co-supported by the Estonian Research Council (PUT633 and PUT1443).

\section{REFERENCES}

[1] Fang Zheng Peng, "Z-source inverter," IEEE Transactions on Industry Applications, vol. 39, no. 2, pp. 504-510 2003.

[2] H. Abu-Rub, A. Iqbal, S. Moin Ahmed, F. Z. Peng, Y. Li and G. Baoming, "Quasi-Z-source inverter-based photovoltaic generation system with maximum power tracking control using ANFIS," IEEE Transactions on Sustainable Energy, vol. 4, no. 1, pp. 11-20 2013

[3] M. K. Nguyen, Y. C. Lim and Y. G. Kim, "TZ-source inverters," IEEE Transactions on Industrial Electronics, vol. 60, no. 12, pp. 568656952013.

[4] W. Qian, F. Z. Peng and H. Cha, "Trans-Z-source inverters," IEEE Transactions on Power Electronics, vol. 26, no. 12, pp. 3453-3463 2011.

[5] R. Strzelecki, M. Adamowicz, N. Strzelecka and W. Bury, "New type T-Source inverter," in 2009 Compatibility and Power Electronics, 2009, pp. 191-195

[6] W. Mo, P. C. Loh, F. Blaabjerg and P. Wang, "Trans-Z-source and $\Gamma$ Z-source neutral-point-clamped inverters," IET Power Electronics, vol. 8, no. 3, pp. 371-377 2015.

[7] W. Mo, P. C. Loh, D. Li and F. Blaabjerg, "Trans-Z-source Neutral Point Clamped inverter," in 6th IET International Conference on Power Electronics, Machines and Drives (PEMD 2012), 2012, pp. 1-5.

[8] B. Ge, H. Abu-Rub, F. Z. Peng, Q. Lei, A. T. de Almeida, F. J. T. E. Ferreira, D. Sun and Y. Liu, "An energy-stored quasi-Z-source inverter for application to photovoltaic power system," IEEE Transactions on Industrial Electronics, vol. 60, no. 10, pp. 4468-4481 2013.

[9] O. Husev, S. Stepenko, C. Roncero-Clemente, E. Romero-Cadaval and D. Vinnikov, "Single phase three-level quasi-z-source inverter with a new boost modulation technique," in IECON 2012 - 38th Annual Conference on IEEE Industrial Electronics Society, 2012, pp. 5852-5857.

[10] IEEE Standard 519-2014 [Online]. Available: http://www.schneiderelectric.com.tw/documents/Event/2016_electrical_en gineering_seminar/IEEE_STD_519_1992vs2014.pdf.

[11] J. Jiao and R. M. Nelms, "Regulating output impedance using a PI controller to improve the stability of a single phase inverter under weak grid," in 2016 IEEE 16th International Conference on Environment and Electrical Engineering (EEEIC), 2016, pp. 1-6.
[12] E. Makovenko, O. Husev, C. Roncero-Clemente, E. RomeroCadaval and F. Blaabjerg, "Single-phase 3L PR controlled qZS inverter connected to the distorted grid," in 2016 10th International Conference on Compatibility, Power Electronics and Power Engineering (CPEPOWERENG), 2016, pp. 234-239.

[13] Jong-Kyu Kim, Jong-Hyun Lee, Hea-Gwang Jeong and Kyo-Beum Lee, "Improvement of grid-connected inverter systems with PR controllers under the unbalanced and distorted grid voltage," in Power Electronics and Motion Control Conference (IPEMC), 2012 7th International, 2012, pp. 1183-1187.

[14] H. Dehghani Tafti, A. I. Maswood, A. Ukil, O. H. P. Gabriel and L. Ziyou, "NPC photovoltaic grid-connected inverter using proportionalresonant controller," in 2014 IEEE PES Asia-Pacific Power and Energy Engineering Conference (APPEEC), 2014, pp. 1-6.

[15] R. Chattopadhyay, A. De and S. Bhattacharya, "Comparison of PR controller and damped PR controller for grid current control of LCL filter based grid-tied inverter under frequency variation and grid distortion," in 2014 IEEE Energy Conversion Congress and Exposition (ECCE), 2014, pp. 3634-3641.

[16] Yushan Liu, Baoming Ge, Haitham Abu-Rub and Dongsen Sun, "Comprehensive modeling of single-phase quasi-Z-source photovoltaic inverter to investigate low-frequency voltage and current ripple," IEEE Transactions on Industrial Electronics, vol. 67, pp. 4194-4202 2015.

[17] Z. Qin, Y. Tang, P. C. Loh and F. Blaabjerg, "Benchmark of AC and DC active power decoupling circuits for second-order harmonic mitigation in kilowatt-scale single-phase inverters," IEEE Journal of Emerging and Selected Topics in Power Electronics, vol. 4, no. 1, pp. 15252016.

[18] Y. Zhou, H. Li and H. Li, "A single-phase PV quasi-Z-source inverter with reduced capacitance using modified modulation and doublefrequency ripple suppression control," IEEE Transactions on Power Electronics, vol. 31, no. 3, pp. 2166-2173 2016.

[19] J. Liao, J. Su, L. Chang and Jidong Lai, "Pulse energy modulation of a single-phase transformer-less inverter with active decoupling," in 2016 IEEE 8th International Power Electronics and Motion Control Conference (IPEMC-ECCE Asia), 2016, pp. 1247-1251.

[20] A. S. Morsy and P. N. Enjeti, "Comparison of active power decoupling methods for high-power-density single-phase inverters using wide-bandgap FETs for google little box challenge," IEEE Journal of Emerging and Selected Topics in Power Electronics, vol. 4, no. 3, pp. 7907982016.

[21] D. Sun, B. Ge, X. Yan, H. Abu-Rub, D. Bi and F. Z. Peng, "Impedance design of quasi-Z source network to limit double fundamental frequency voltage and current ripples in single-phase quasi- $Z$ source inverter," in 2013 IEEE Energy Conversion Congress and Exposition, 2013, pp. 2745-2750.

[22] Yushan Liu, Haitham Abu-Rub, Baoming Ge, Frede Blaabjerg, Omar Ellabban and Poh Chiang Loh, Design of Z-Source and Quasi-ZSource Inverters, 2016.

[23] O. Husev, C. Roncero-Clemente, E. Romero-Cadaval, D. Vinnikov and S. Stepenko, "Single phase three-level neutral-point-clamped quasi-Zsource inverter," IET Power Electronics, vol. 8, no. 1, pp. 1-10 2015. [24] O. Husev, C. Roncero-Clemente, E. Romero-Cadaval, D. Vinnikov and T. Jalakas, "Three-level three-phase quasi-Z-source neutral-pointclamped inverter with novel modulation technique for photovoltaic application," Electr.Power Syst.Res., vol. 130, pp. 10-21, 12016.

[25] J. Liu, J. Hu and L. Xu, "Dynamic modeling and analysis of Z source Converter-Derivation of AC small signal model and designoriented analysis," IEEE Transactions on Power Electronics, vol. 22, no. 5, pp. 1786-1796 2007.

[26] O. Husev, R. Strzelecki, F. Blaabjerg, V. Chopyk, and D. Vinnikov, "Novel family of single-phase modified impedance-source buck-boost multilevel inverters with reduced switch count," IEEE Trans. on Power Electron., vol. 31, no. 11, pp. 7580-7591, Nov 2016.

[27] Y. Li and F. Z. Peng, "AC small signal modeling, analysis and control of quasi-Z-Source Converter," in Proceedings of the 7th International Power Electronics and Motion Control Conference, 2012, pp. 1848-1854.

This is a post-print of a paper published in Proceedings of the 2017 11th IEEE International Conference on Compatibility, Power Electronics and Power Engineering (CPE-POWERENG 2017) https://doi.org/10.1109/CPE.2017.7915225 and is subject to IEEE copyright. 